Article

\title{
Supramolecular Assembly of Gold Nanoparticles on Carbon Nanotubes: Application to the Catalytic Oxidation of Hydroxylamines
}

\author{
Nimesh Shah ${ }^{1,2, \dagger}$, Pallabita Basu ${ }^{1, \dagger}$, Praveen Prakash ${ }^{2, \dagger}$, Simon Donck ${ }^{1,2}$, Edmond Gravel $^{2}$, \\ Irishi N. N. Namboothiri ${ }^{1, *}$ and Eric Doris ${ }^{2, *}$ \\ 1 Department of Chemistry, Indian Institute of Technology, Bombay, Mumbai 400076, India; \\ nimesh31@yahoo.com (N.S.); pallabita17@gmail.com (P.B.); simon.donck@gmail.com (S.D.) \\ 2 Alternative Energies and Atomic Energy Commission (CEA), Saclay Institute of Biology and \\ Technology (IBITECS), Department of Bioorganic Chemistry and Isotopic Labeling, 91191 Gif-sur-Yvette, \\ France; praveen.prakash@cea.fr (P.P.); edmond.gravel@cea.fr (E.G.) \\ * Correspondence: irishi@chem.iitb.ac.in (I.N.N.N.); eric.doris@cea.fr (E.D.); \\ Tel.: +91-2225767196 (I.N.N.N.); +33-169088071 (E.D.) \\ + These authors contributed equally to this work.
}

Academic Editors: Hermenegildo García and Sergio Navalón

Received: 19 January 2016; Accepted: 16 February 2016; Published: 24 February 2016

\begin{abstract}
A supramolecular heterogeneous catalyst was developed by assembly and stabilization of gold nanoparticles on the surface of carbon nanotubes. A layer-by-layer assembly strategy was used and the resulting nanohybrid was involved in the catalytic oxidation of hydroxylamines under mild conditions. The nanohybrid demonstrated high efficiency and selectivity on hydroxylamine substrates.
\end{abstract}

Keywords: carbon nanotubes; gold nanoparticles; nanohybrid; heterogeneous catalysis

\section{Introduction}

Besides stoichiometric approaches that are routinely used for the oxidation of organic substrates [1,2], catalytic processes have also been devised to perform selective oxidation reactions [3]. With heterogeneous catalytic systems, obtained by assembling the metallic catalysts on a solid support, facile reclaim and reuse of the catalytic species can be achieved [4]. Among the various platforms used as supports, allotrope forms of carbon, in particular carbon nanotubes (CNTs), have been shown to provide some key advantages [5]. The latter include chemical, thermal, and mechanical stability, high specific surface area, inertness, and adjustable topography. CNTs are also able to act in a synergistic fashion to enhance the performances of the supported catalytic metal [6,7]. With these features in mind, we sought to develop a catalyst that could catalyze some oxidation reactions under mild conditions of temperature and pressure using low catalytic loadings. Herein, we report the assembly of a CNT-gold nanohybrid catalyst and its application to the selective oxidation of hydroxylamines into either nitroso or azoxy derivatives.

\section{Results and Discussion}

\subsection{Assembly of the AuCNT Nanohybrid}

Although gold has long been regarded as a poor catalytic metal, its nanosized forms [8], including supported ones $[9,10]$, have recently been shown to be able to catalyze a wide array of chemical transformations. Our CNT-gold catalyst was built using a layer-by-layer approach that was adapted 
from our previous work [11-23]. Carbon nanotubes were first dispersed in an aqueous solution by ultrasonication in the presence of an amphiphilic nitrilotriacetic-diyne (DANTA) surfactant. This first step led to the non-stochastic assembly of the amphiphilic units on the CNT surface and to the formation of supramolecular structures with a nanoring-like shape (Figure 1a,c). This type of well-ordered supramolecular assembly on CNTs was first reported in 2003 [24]. Amphiphilic DANTA adsorbed at the surface of the nanotubes by hydrophobic interactions while its hydrophilic polar head was pointing toward the aqueous medium. The rings were polymerized by ultraviolet (UV) irradiation in a second step. In fact, irradiation of the sample for $6 \mathrm{~h}$ at $254 \mathrm{~nm}$ led to a topochemical polymerization of the diyne motif incorporated in the hydrophobic part of the starting amphiphile $[25,26]$. Polymerization takes place within individual half-cylinders and strengthens the cohesion of the assembly. After UV irradiation, the DANTA-decorated nanotubes became resistant to dialysis against water and to ethanol washes, indicating that the lipid assemblies had been polymerized. The second layer was thereafter deposited by stirring the suspended nanotubes with a cationic polymer, poly(diallyldimethylammonium chloride) (PDADMAC), which adsorbed on the nanotube's surface by electrostatic interactions with the primary anionic layer. The double-coated CNTs were then recovered by centrifugation before the final deposition of gold nanoparticles (AuNPs). The latter were prepared in parallel by reduction of $\mathrm{HAuCl}_{4}$ in the presence of tetrahydroxymethylphosphonium chloride [27]. The colloidal suspension of gold nanoparticles (AuNPs) was then sequentially added to the coated CNTs in which the polyammonium network provided robust anchoring and stabilization of the metallic nanoparticles (Figure $1 b, d$ ). The AuCNT nanohybrid was finally suspended in water and used for the catalysis of the reported reactions.
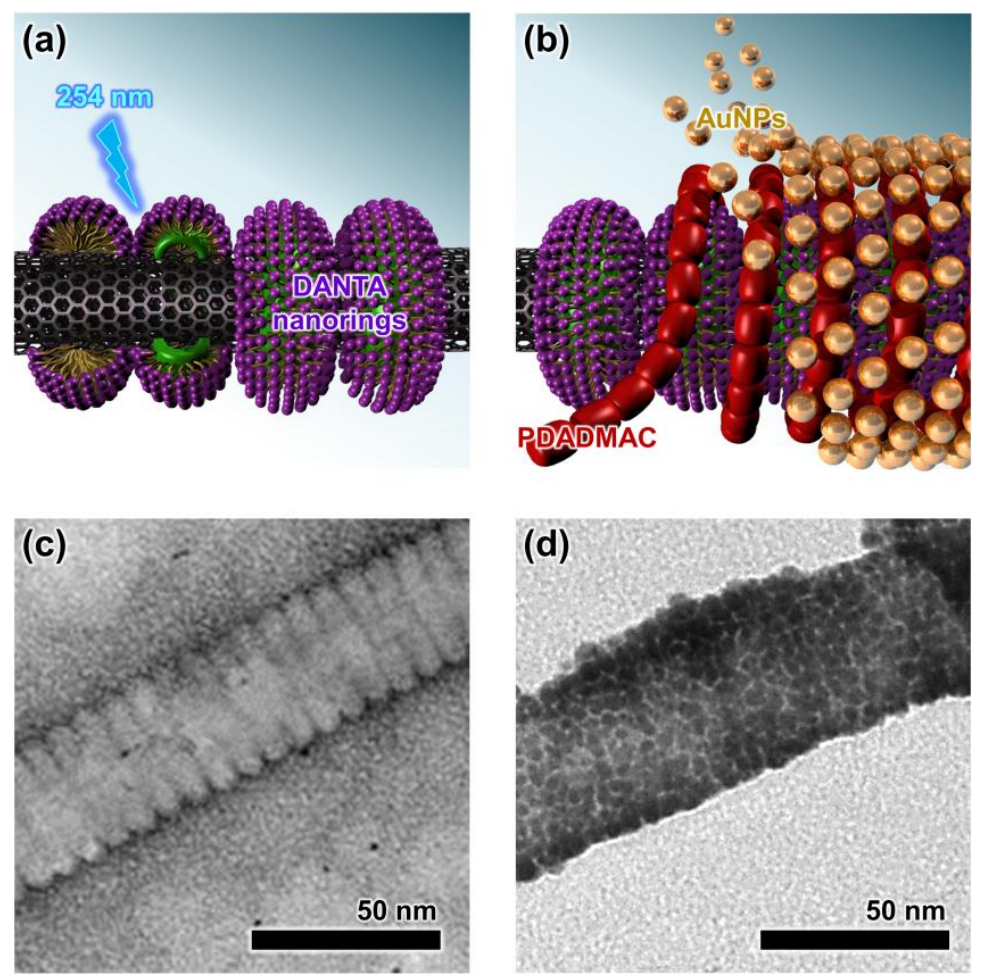

Figure 1. (a) Schematic representation of nitrilotriacetic-diyne (DANTA) nanoring polymerization on the carbon nanotube (CNT) surface; (b) Schematic representation of the final stages of the AuCNT synthesis; (c) Transmission electron microscopy (TEM) image of polymerized DANTA nanorings on CNT (negative staining); (d) TEM image of the AuCNT final catalyst. 


\subsection{Characterization of the AuCNT Nanohybrid}

Transmission electron microscopy (TEM, Philips CM12 microscope, Amsterdam, the Netherlands) indicated that the AuNPs were of spherical shape. The average size of the supported nanoparticles was measured using TEM pictures. Statistical measurement indicated that the supported AuNPs had an average diameter of $c a .3 \mathrm{~nm}$ (Figure 2a). The metal content of the aqueous AuCNT suspension was determined by inductively coupled plasma mass spectrometry (ICP-MS) ([Au] $=1.2 \mathrm{mM})$. Finally, the metallic character of the supported gold nanoparticles was established by X-ray photoelectron spectroscopy (XPS, VG ESCALAB 210 spectrometer, Waltham, MA, USA) analysis which showed characteristic Au 4f-binding energies contributions of Au [28] (Figure 2b).

(a)

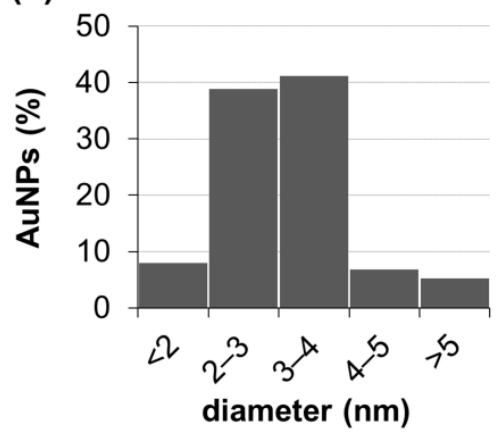

(b)

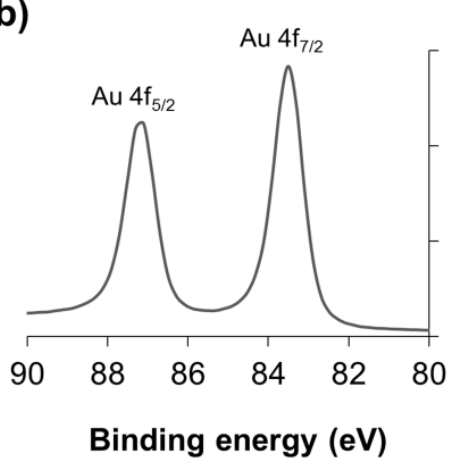

Figure 2. (a) Size distribution obtained from the measurement of 250 gold particles; (b) X-ray photoelectron spectroscopy (XPS) analysis (Au $4 \mathrm{f}$ core level) of the AuCNT nanohybrid.

\subsection{Oxidation of Hydroxylamines with the AuCNT Nanohybrid}

With the gold-based nanohybrid in hand, we investigated its potential in the aerobic oxidation of hydroxylamines. In the latter transformation, we expected the formation of the corresponding nitroso derivatives [29]. The nanohybrid-catalyzed oxidation of tert-butyl hydroxylamine (1a) in $\mathrm{CHCl}_{3} / \mathrm{H}_{2} \mathrm{O}$ afforded tert-butyl nitroso compound $\mathbf{1 b}$ in $81 \%$ yield after $12 \mathrm{~h}$ of reaction (Table 1 , Entry 1). The use of a binary solvent mixture permitted us to increase the rate of the reaction and afforded a more selective transformation. The reaction of $\mathrm{N}$-cyclohexylhydroxylamine (2a) also cleanly produced nitrosocyclohexane ( $\mathbf{2 b}$ ) in $83 \%$ yield (Entry 2 ). It is noteworthy that no isomerization of nitrosocyclohexane ( $\mathbf{2} \mathbf{b})$ into the corresponding cyclohexanone oxime was detected. This result is to be noted since tautomerization of nitroso compounds to oximes is classically observed when working with substrates carrying $C \alpha$-protons. The reaction of aliphatic substrates thus satisfactorily provided access to nitroso compounds in high yields, but aromatic hydroxylamines did not behave similarly.

Table 1. Oxidation of various hydroxylamines with AuCNT [a].

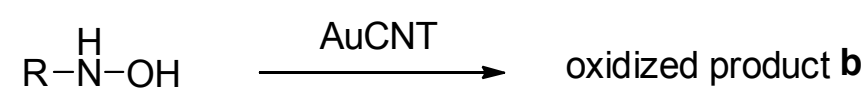

a

\begin{tabular}{clll}
\hline Entry & Substrate a & Product b & Yield (\%) \\
\hline & & & \\
\hline
\end{tabular}


Table 1. Cont.

Entry

[a] Conditions: $N$-hydroxylamine $(0.1 \mathrm{mmol}), \mathrm{AuCNT}(0.5 \mathrm{~mol} \%), \mathrm{K}_{2} \mathrm{CO}_{3}(0.2 \mathrm{mmol})$, room temperature under air. [b] Reaction time $12 \mathrm{~h}, \mathrm{CHCl}_{3} / \mathrm{H}_{2} \mathrm{O}(1: 1,2 \mathrm{~mL})$. [c] Reaction time $2 \mathrm{~h}, \mathrm{CHCl}_{3}(2 \mathrm{~mL})$.

For example, the reaction of phenylhydroxylamine (3a) with $\mathrm{AuCNT}$ in $\mathrm{CHCl}_{3}$ gave a dimeric product in the form of the azoxy derivative $\mathbf{3 b}$ in $2 \mathrm{~h}$ only (Entry 3 ). It is noteworthy that the binary solvent system was not required in the case of aromatic hydroxylamine substrates. A possible mechanism for the conversion observed in entry 3 (formation of the azoxy compound) could involve the oxidation of phenylhydroxylamine (3a) into the corresponding nitroso derivative 3a' (Scheme 1). As 3a' accumulates in the solution, its condensation with the unreacted phenylhydroxylamine (3a) leads to the formation of azoxy derivative $\mathbf{3} \mathbf{b}$, after the elimination of a molecule of water.

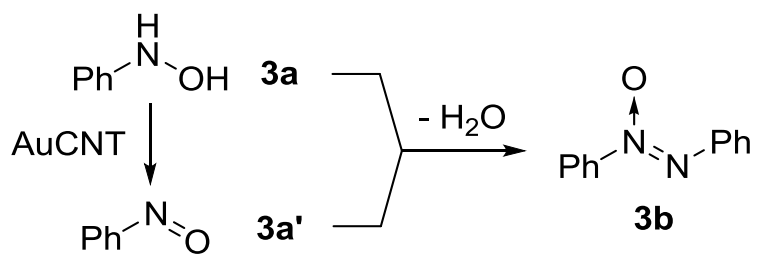

Scheme 1. Postulated mechanism for the formation of azoxy compounds.

The same type of reactivity was also evidenced for other aromatic substrates such as 4-chlorophenylhydroxylamine (4a, Entry 4) and 4-fluorophenylhydroxylamine (5a, Entry 5). Indeed, we detected the formation of azoxy dimers $\mathbf{4 b}$ (98\% yield) and $\mathbf{5 b}$ ( $92 \%$ yield) starting from compounds $4 \mathbf{a}$ and $\mathbf{5 a}$, respectively. The transformation worked equally well on benzylhydroxylamine (6a) in 94\% yield (Entry 6) but failed on the more hindered 2,6-dimethylphenylhydroxylamine (7a, Entry 7) which remained unaffected. 


\subsubsection{Recycling of the AuCNT Nanohybrid}

To assess the recyclability of the AuCNT nanohybrid, multiple oxidation cycles were carried out by successive reuse of the same sample of catalyst. A classical oxidation reaction was set using the general procedure described above which was applied to $\mathrm{N}$-phenylhydroxylamine (3a). After completion, the catalyst was recovered by centrifugation, and the supernatant was worked up. The catalyst was washed with tetrahydrofuran (THF) and reused in subsequent oxidation reactions. This process was repeated over five consecutive cycles and showed no significant decrease in yields of oxidized azo product $3 \mathbf{b}$ (Table 2). After the fifth run, TEM analysis showed no major alteration of the nanohybrid morphology. The use of non-supported AuNPs provided lower yields of product and the catalyst could not be recycled.

Table 2. Recycling of AuCNT for the oxidation of N-phenylhydroxylamine.

\begin{tabular}{|c|c|c|c|c|}
\hline & \multirow{2}{*}{$\mathrm{Ph}_{\mathrm{H}^{\mathrm{N}}}$} & \multirow{2}{*}{$\underset{\mathrm{CHCl}_{3}, 2 \mathrm{~h}}{\stackrel{\mathrm{AuCNT}(0.5 \mathrm{~mol} \%)}{\longrightarrow}}$} & \multirow[t]{2}{*}{ 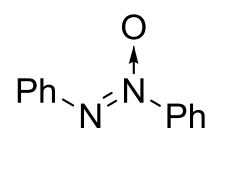 } & \multirow[t]{2}{*}{$3 b$} \\
\hline & & & & \\
\hline & Entry & AuCNT & Yield (\%) & \\
\hline & 1 & fresh & 96 & \\
\hline & 2 & 1st reuse & 93 & \\
\hline & 3 & 2nd reuse & 91 & \\
\hline & 4 & 3rd reuse & 93 & \\
\hline & 5 & 4 th reuse & 94 & \\
\hline
\end{tabular}

\subsubsection{Is AuCNT a Heterogeneous Catalyst?}

The involvement of the nanohybrid in the oxidation process was demonstrated by the following experiment. A standard oxidation reaction of $\mathrm{N}$-phenylhydroxylamine (3a) was run and, after $45 \mathrm{~min}$, split into two. At this stage, approximately $50 \%$ conversion of $3 a$ into the corresponding azoxy derivative $3 \mathbf{b}$ was detected by ${ }^{1} \mathrm{H}-\mathrm{NMR}$ (Bruker Avance DPX $400 \mathrm{MHz}$ spectrometer, Billerica, MA, USA). The AuCNT catalyst was removed by centrifugation in one sample, whereas it was left in the other. Both reactions were further stirred for additional time before analysis. While the reaction was nearly quantitative ( $c a .95 \%$ yield) in the AuCNT-containing sample, no further conversion was detected in the absence of the nanohybrid. These observations confirmed that oxidation of $N$-phenylhydroxylamine (3a) occurred at the surface of the AuCNT nanohybrid which acted as a solid catalyst [30] and whose performances are comparable to that of a previously developed rhodium-carbon nanotube catalytic system [23].

\section{Experimental Section}

\subsection{Assembly of the Nanohybrid}

Amphiphilic DANTA ( $20 \mathrm{mg}$ ) was dissolved in $2 \mathrm{~mL}$ of $25 \mathrm{mM}$ pH 8 aqueous Tris-buffer before multiwalled carbon nanotubes $(50 \mathrm{mg}$ ) were added. The dispersion was sonicated and the stable suspension transferred into two tubes. The tubes were centrifuged at $5000 \times g$ and the supernatants were collected. The latter were centrifuged at $15,000 \times g$ for $45 \mathrm{~min}$. The supernatant was discarded and the pellets taken in buffer and centrifuged again at $15,000 \times \mathrm{g}$ for $45 \mathrm{~min}$. The pellets were finally resuspended in $1.5 \mathrm{~mL}$ of buffer and submitted to UV irradiation at $254 \mathrm{~nm}$ for $6 \mathrm{~h}$.

After polymerization, the buffer volume was adjusted to $1.5 \mathrm{~mL}$. The suspension was stirred in the presence of the cationic polymer PDADMAC ( $700 \mu \mathrm{L}$ of a $20 \%$ water solution) for $1 \mathrm{~h}$. The ensuing centrifugation at $15,000 \times g$ for $30 \mathrm{~min}$ permitted to get rid of the polymer in excess. The pellets were taken in $2 \mathrm{~mL}$ of buffer. This operation was repeated twice using the buffer solution and two more times using pure water. 
The final pellets were resuspended in $1 \mathrm{~mL}$ of water. Then $50 \mu \mathrm{L}$ of the latter suspension was transferred to Eppendorf ${ }^{\circledR}$ tubes $(\times 20)$. To each tube was added $1 \mathrm{~mL}$ of a $1 \mathrm{mM}$ colloid suspension of the gold nanoparticles [27] and the mixture was vortex-stirred at room temperature for $1 \mathrm{~min}$ every $30 \mathrm{~min}$ (during $4 \mathrm{~h}$ ). The suspension was then centrifuged at $3000 \times g$ for $5 \mathrm{~min}$. The supernatant was discarded and $1 \mathrm{~mL}$ of a fresh gold colloid suspension was added. The same process was repeated two more times. The pellets were washed three times by centrifugation/redispersion in water. The 20 pellets were combined and $4 \mathrm{~mL}$ of water was finally added.

\subsection{Procedure for the Oxidation of Hydroxylamines}

A typical procedure is given for the oxidation of $N$-cyclohexylhydroxylamine 2a. Under air, to a stirred solution of $\mathrm{N}$-cyclohexylhydroxylamine hydrochloride (2a.HCl, $0.1 \mathrm{mmol})$ in $2 \mathrm{~mL}$ of $\mathrm{CHCl}_{3} / \mathrm{H}_{2} \mathrm{O}$ (1:1) was added $\mathrm{K}_{2} \mathrm{CO}_{3}$ (2 equivalents) and $0.5 \mathrm{~mol} \%$ of the suspension of the AuCNT catalyst. The reaction mixture was stirred at room temperature for $12 \mathrm{~h}$. The aqueous layer was extracted with $\mathrm{CHCl}_{3}$. The combined organic layer was dried over anhydrous $\mathrm{Na}_{2} \mathrm{SO}_{4}$, filtered, and concentrated under vacuum. The crude residue was purified by column chromatography to afford nitroso-cyclohexyl amine $\mathbf{2 b}$ in $83 \%$ yield. ${ }^{1} \mathrm{H}-\mathrm{NMR}\left(400 \mathrm{MHz}, \mathrm{CDCl}_{3}\right) \delta(\mathrm{ppm}) 5.07$ (triplet of triplet, $J=3.8 \mathrm{~Hz}, J=11.6 \mathrm{~Hz}, 1 \mathrm{H}$ ), 1.97-1.94 (multiplet, 2H), 1.89-1.86 (multiplet, 2H), 1.69-1.65 (multiplet, 2H), 1.43-1.31 (multiplet, $2 \mathrm{H}), 1.28-1.20$ (multiplet, $2 \mathrm{H}) ;{ }^{13} \mathrm{C}-\mathrm{NMR}\left(100 \mathrm{MHz}, \mathrm{CDCl}_{3}\right) \delta$ (ppm) 65.6, $28.2(2 \mathrm{C}), 25.0,24.5(2 \mathrm{C})$.

\section{Conclusions}

A nanohybrid catalyst was produced by the layer-by-layer supramolecular assembly of gold nanoparticles on carbon nanotubes. The gold-based nanohybrid (AuCNT) was employed in the oxidation of hydroxylamines to provide straightforward access to the corresponding oxidized products in good to excellent yields. The transformation led either to nitroso derivatives in the case of aliphatic hydroxylamines or azoxy derivatives in the case of aromatic/benzylic hydroxylamines. Selectivity, low catalyst loading and mild reaction conditions (e.g., room temperature, open air) are the salient features of the AuCNT methodology.

Acknowledgments: Supports from the Indo-French Centre for the Promotion of Advanced Research (IFCPAR)/Centre Franco-Indien pour la Promotion de la Recherche Avancée (CEFIPRA) (Project No. 4705-1) and from the CEA-Enhanced Eurotalents program are gratefully acknowledged. The TEM-team platform (CEA, IBITECS) is acknowledged for help with TEM images. The "Service de Chimie Bioorganique et de Marquage" belongs to the Laboratory of Excellence in Research on Medication and Innovative Therapeutics (ANR-10-LABX-0033-LERMIT).

Author Contributions: N.S., P.B., P.P. and S.D. performed the experiments. E.G., I.N.N.N. and E.D. designed the experiments and wrote the manuscript.

Conflicts of Interest: The authors declare no conflict of interest.

\section{References}

1. Donohoe, T.J. Oxidation and Reduction in Organic Synthesis; Oxford University Press: Oxford, UK, 2000.

2. Hussain, H.; Green, I.R.; Ahmed, I. Journey describing applications of oxone in synthetic chemistry. Chem. Rev. 2013, 113, 3329-3371. [CrossRef] [PubMed]

3. Van Santen, R.A. Catalytic Oxidation: Principles and Applications; Sheldon, R.A., van Santen, R.A., Eds.; World Scientific: Singapore, 1995.

4. Ali, M.E.; Shaheen, M.M.; Sarkar, M.; Hamid, S.B.A. Heterogeneous metal catalysts for oxidation reactions. J. Nanomater. 2014, 2014. [CrossRef]

5. John, J.; Gravel, E.; Namboothiri, I.N.N.; Doris, E. Advances in carbon nanotube-noble metal catalyzed organic transformations. Nanotechnol. Rev. 2012, 1, 515-539. [CrossRef]

6. Singh, R.; Premkumar, T.; Shin, J.Y.; Geckeler, K.E. Carbon nanotube and gold-based materials: A symbiosis. Chem. Eur. J. 2010, 16, 1728-1743. [CrossRef] [PubMed] 
7. Melchionna, M.; Marchesan, S.; Prato, M.; Fornasiero, P. Carbon nanotubes and catalysis: The many facets of a successful marriage. Catal. Sci. Technol. 2015, 5, 3859-3875. [CrossRef]

8. Zhang, Y.; Cui, X.; Shi, F.; Deng, Y. Nano-gold catalysis in fine chemical synthesis. Chem. Rev. 2012, 112, 2467-2505. [CrossRef] [PubMed]

9. Gravel, E.; Namboothiri, I.N.N.; Doris, E. Supramolecular assembly of gold nanoparticles on carbon nanotubes and catalysis of selected organic transformations. Synlett 2016, 27. [CrossRef]

10. Stratakis, M.; Garcia, H. Catalysis by supported gold nanoparticles: Beyond aerobic oxidative processes. Chem. Rev. 2012, 112, 4469-4506. [CrossRef] [PubMed]

11. John, J.; Gravel, E.; Hagège, A.; Li, H.; Gacoin, T.; Doris, E. Catalytic oxidation of silanes by carbon nanotube-gold nanohybrid. Angew. Chem. Int. Ed. 2011, 50, 7533-7536. [CrossRef] [PubMed]

12. Kumar, R.; Gravel, E.; Hagège, A.; Li, H.; Jawale, D.V.; Verma, D.; Namboothiri, I.N.N.; Doris, E. Carbon nanotube-gold nanohybrids for selective catalytic oxidation of alcohols. Nanoscale 2013, 5, 6491-6497. [CrossRef] [PubMed]

13. Kumar, R.; Gravel, E.; Hagège, A.; Li, H.; Verma, D.; Namboothiri, I.N.N.; Doris, E. Direct reductive amination of aldehydes catalyzed by CNT-gold nanohybrids. ChemCatChem 2013, 5, 3571-3575. [CrossRef]

14. Jawale, D.V.; Gravel, E.; Geertsen, V.; Li, H.; Shah, N.; Namboothiri, I.N.N.; Doris, E. Aerobic oxidation of phenols and related compounds using carbon nanotube-gold nanohybrid catalysts. ChemCatChem 2014, 6, 719-723. [CrossRef]

15. Jawale, D.V.; Gravel, E.; Geersten, V.; Li, H.; Shah, N.; Namboothiri, I.N.N.; Doris, E. Size effect of gold nanoparticles supported on carbon nanotube as catalysts in selected organic reactions. Tetrahedron 2014, 70, 6140-6145. [CrossRef]

16. Shah, N.; Gravel, E.; Jawale, D.V.; Doris, E.; Namboothiri, I.N.N. Carbon nanotube-gold nanohybrid catalyzed $\mathrm{N}$-formylation of amines using aqueous formaldehyde. ChemCatChem 2014, 6, 2201-2205. [CrossRef]

17. Shah, N.; Gravel, E.; Jawale, D.V.; Doris, E.; Namboothiri, I.N.N. Synthesis of quinoxalines via carbon nanotube-gold nanohybrid catalyzed cascade reaction of vicinal diols and ketoalcohols with diamines. ChemCatChem 2015, 7, 57-61. [CrossRef]

18. Jawale, D.V.; Gravel, E.; Boudet, C.; Shah, N.; Geertsen, V.; Li, H.; Namboothiri, I.N.N.; Doris, E. Selective conversion of nitroarenes using a carbon nanotube-ruthenium nanohybrid. Chem. Commun. 2015, 51, 1739-1742. [CrossRef] [PubMed]

19. Jawale, D.V.; Gravel, E.; Boudet, C.; Shah, N.; Geertsen, V.; Li, H.; Namboothiri, I.N.N.; Doris, E. Room temperature Suzuki coupling of aryl iodides, bromides, and chlorides using a heterogeneous carbon nanotube-palladium nanohybrid catalyst. Catal. Sci. Technol. 2015, 5, 2388-2392. [CrossRef]

20. Jawale, D.V.; Gravel, E.; Shah, N.; Dauvois, V.; Li, H.; Namboothiri, I.N.N.; Doris, E. Cooperative dehydrogenation of $N$-heterocycles using a carbon nanotube-rhodium nanohybrid. Chem. Eur. J. 2015, 21, 7039-7042.

21. Donck, S.; Gravel, E.; Shah, N.; Jawale, D.V.; Doris, E.; Namboothiri, I.N.N. Tsuji-Wacker oxidation of terminal olefins using a palladium-carbon nanotube nanohybrid. ChemCatChem 2015, 7, 2318-2322. [CrossRef]

22. Donck, S.; Gravel, E.; Shah, N.; Jawale, D.V.; Doris, E.; Namboothiri, I.N.N. Deoxygenation of amine N-oxides using gold nanoparticles supported on carbon nanotubes. RSC Adv. 2015, 5, 50865-50868. [CrossRef]

23. Donck, S.; Gravel, E.; Li, A.; Prakash, P.; Shah, N.; Leroy, J.; Namboothiri, I.N.N.; Doris, E. Mild and selective catalytic oxidation of organic substrates by a carbon nanotube-rhodium nanohybrid. Catal. Sci. Technol. 2015, 5, 4542-4546. [CrossRef]

24. Richard, C.; Balavoine, F.; Schultz, P.; Ebbesen, T.W.; Mioskowski, C. Supramolecular self-assembly of lipid derivatives on carbon nanotubes. Science 2003, 300, 775-778. [CrossRef] [PubMed]

25. Ogawa, K.; Tamura, H.; Hatada, M.; Ishihara, T. Study of photoreaction processes of PDA Langmuir films. Langmuir 1988, 4, 903-906. [CrossRef]

26. Shimizu, T.; Masuda, M.; Minamikawa, H. Supramolecular nanotube architectures based on amphiphilic molecules. Chem. Rev. 2005, 105, 1401-1443. [CrossRef] [PubMed]

27. Duff, D.G.; Baiker, A.; Edwards, P.P. A new hydrosol of gold clusters. Formation and particle size variation. Langmuir 1993, 9, 2301-2309. [CrossRef]

28. Conte, M.; Hutchings, G.H. Modern Gold Catalyzed Synthesis; Hashmi, A.S.K., Toste, F.D., Eds.; Wiley-VCH: Weinheim, Germany, 2012. 
29. Gowenlock, B.G.; Richter-Addo, G.B. Preparations of C-nitroso compounds. Chem. Rev. 2004, 104, 3315-3340. [CrossRef] [PubMed]

30. Astruc, D.; Lu, F.; Aranzaes, J.R. Nanoparticles as recyclable catalysts: The frontier between homogeneous and heterogeneous catalysis. Angew. Chem. Int. Ed. 2005, 44, 7852-7872. [CrossRef] [PubMed]

(C) 2016 by the authors; licensee MDPI, Basel, Switzerland. This article is an open access article distributed under the terms and conditions of the Creative Commons by Attribution (CC-BY) license (http://creativecommons.org/licenses/by/4.0/). 